\title{
Development of Electrode Materials of Lithium-Ion Battery Utilizing Nanospaces
}

\author{
Takunori Minamisawa ${ }^{1}$, Kyoichi Oshida ${ }^{1, *}$, Nozomi Kobayashi ${ }^{1}$, Akinobu Ando ${ }^{1}$, \\ Daiki Misawa ${ }^{1}$, Tomoyuki Itaya ${ }^{1}$, Minoru Moriyama ${ }^{1}, K_{0 z o}$ Osawa ${ }^{1}$, Toshimitsu Hata ${ }^{2}$, \\ Yuta Sugiyama ${ }^{3}$, Hiroto Iguchi ${ }^{3}$ and Naoya Kobayashi ${ }^{4}$ \\ 1 National Institute of Technology, Nagano College, Nagano 381-8550, Japan; 16907@g.nagano-nct.ac.jp (T.M.); \\ 13419@g.nagano-nct.ac.jp (N.K.); 13403@g.nagano-nct.ac.jp (A.A.); 14433@g.nagano-nct.ac.jp (D.M.); \\ itaya@nagano-nct.ac.jp (T.I.); moriyama@nagano-nct.ac.jp (M.M.); ohsawa@nagano-nct.ac.jp (K.O.) \\ 2 Research Institute for Sustainable Humanosphere of Kyoto University, Uji, Kyoto 611-0011, Japan; \\ hata@rish.kyoto-u.ac.jp \\ 3 Interdisciplinary Graduate School of Science and Technology, Shinshu University, Nagano 380-8553, Japan; \\ sugiyama@endomoribu.shinshu-u.ac.jp (Y.S.); iguchi@endomoribu.shinshu-u.ac.jp (H.I.) \\ 4 TOC Capacitor Co., Ltd., Okaya, Nagano 394-0035, Japan; naoya.kobayashi@tocc.co.jp \\ * Correspondence: oshida@nagano-nct.ac.jp; Tel.: +81-26-295-7092
}

Received: 28 February 2018; Accepted: 5 April 2018; Published: 13 April 2018

\begin{abstract}
To develop high capacity electrode materials for lithium-ion battery (LIB), dissimilar materials are mixed and, as a result, carbon nanofibers containing silicon (Si) nanoparticles and its components are successfully created by electrospinning method and some heat treatments. Tetraethoxysilane (TEOS) and Si nanoparticles are adopted as additives of carbon nanofibers because of their huge potential for obtaining high capacity. In this research, therefore, we develop TEOS/Si hybrid carbon nanofibers. Consequently, some samples obtain much higher charging/discharging capacity than the theoretical capacity for graphite $\left(372 \mathrm{mAh} / \mathrm{g}, \mathrm{LiC}_{6}\right)$ even after second cycle.
\end{abstract}

Keywords: lithium-ion battery (LIB); anode; silicon; TEOS; carbon nanofiber; electrospinning; hybrid electrode

\section{Introduction}

Lithium-ion batteries (LIBs) are widely used for many industrial products currently. The purpose of this research is to develop high capacity anode electrode materials for LIB. It is necessary to obtain much higher capacity than the theoretical capacity for graphite since much wider utilization of LIBs is expected in the future. For the achievement of this purpose, carbon nanofibers containing $\mathrm{Si}$ nanoparticles and its components are created.

The alloy-type anode electrode material using Si has the largest charging/discharging capacity among the materials examined so far $(4200 \mathrm{mAh} / \mathrm{g}), \geq 10$ times than that of graphite [1]. There are, however, some problems when $\mathrm{Si}$ is adopted as an anode material. The volume of $\mathrm{Si}$ increases by $300-400 \%$ when Li is inserted into Si during charging. The repetition of these charging/discharging cycles generates a large amount of stress in the anode electrode material, and it causes the destruction of the electrode. In this research, we overcome these problems by wrapping Si nanoparticles using the carbon nanofibers. 


\section{Materials and Methods}

\subsection{Carbon Nanofibers Synthesized via Electrospinning}

In this research, carbon nanofibers containing dissimilar materials were created by electrospinning method and some heat treatments. Preparation of the carbon nanofibers via electrospinning process is listed in Table 1 [2]. As a carbon precursor, PAN (polyacrylonitrile) was adopted since it has been used in the production of commercial carbon fibers. In addition, DMF ( $N, N$-dimethylformamide) was used as a solvent. TEOS (tetraethoxysilane, chemical formula; $\mathrm{SiC}_{8} \mathrm{H}_{20} \mathrm{O}_{4}$ ) and $\mathrm{Si}$ nanoparticles were mixed in PAN/DMF solution as additives. The Si nanoparticles were, incidentally, carbon-coated Si, i.e., a thin carbon layer $(2-3 \mathrm{~nm})$ surrounded the surface of the Si nanoparticles [3].

Table 1. Preparation of the carbon nanofibers via electrospinning.

\begin{tabular}{ccccc}
\hline Sample Names & Precursor and Additives/Solvent & $\begin{array}{c}\text { Spinning } \\
\text { Conditions }\end{array}$ & Stabilization & Carbonization \\
\hline TEOS Carbon & $10 \mathrm{wt} \%[\mathrm{PAN}+\mathrm{TEOS}(7: 3)] / \mathrm{DMF}$ & $25 \mathrm{kV} / 15 \mathrm{~cm}$ & $260{ }^{\circ} \mathrm{C}$ & $1000{ }^{\circ} \mathrm{C}$ \\
$\begin{array}{c}\text { TEOS } / \mathrm{Si} \text { Hybrid } \\
\text { Carbon }\end{array}$ & {$[10 \mathrm{wt} \%[\mathrm{PAN}+\mathrm{TEOS}(7: 3)]+1 \mathrm{wt} \% \mathrm{Si}] / \mathrm{DMF}$} & $23 \mathrm{kV} / 15 \mathrm{~cm}$ & $240{ }^{\circ} \mathrm{C}$ & $700{ }^{\circ} \mathrm{C}$ \\
\hline
\end{tabular}

To increase the heat resistance of the materials, stabilization processes at $240{ }^{\circ} \mathrm{C}$ or $260{ }^{\circ} \mathrm{C}$ in air were applied. Afterwards, the stabilized nanofibers were carbonized in $\mathrm{N}_{2}$ atmosphere at $700{ }^{\circ} \mathrm{C}$ or $1000^{\circ} \mathrm{C}$. Carbon nanofibers containing dissimilar materials were finally created.

\subsection{Characterization of Carbon Nanofibers}

Structures of the carbon nanofibers were observed by scanning electron microscopy (SEM, HITACHI, SU3500, Tokyo, Japan), energy dispersive X-ray diffraction (EDX, Oxford Instruments, X-Max, Abingdon, UK) and transmission electron microscopy (TEM, JEOL, JEM2100F, Tokyo, Japan). In addition, precise structures of the materials were determined using X-ray diffraction (XRD, Rigaku, SmartLab, Tokyo, Japan) and Raman scattering equipment (Kaiser, Hololab, Ann Arbor, MI, USA).

\subsection{Electrochemical Characterization}

\subsubsection{Electrode Made of Nickel Mesh}

Pulverized carbon nanofibers, vapor-grown carbon fiber (VGCF, Showa Denko K.K.) and polyvinylidene difluoride (PVDF) were mixed and they were settled on the nickel (Ni) mesh. The mixing ratio of VGCF was $10 \%$ of the carbon nanofibers. The mixing ratio of PVDF to the carbon nanofibers and VGCF was 1:1. After the settlement, the sample was pressurized at $10 \mathrm{MPa}$ for $5 \mathrm{~min}$. The cell and separator were CR2032-type and TF4850-type, respectively. For electrochemical experiments of the coin cell, constant current (CC) charging/discharging was adopted in this experiment. Current density was $30 \mathrm{~mA} / \mathrm{g}$, and charging/discharging processes ceased at $1 \mathrm{mV}$.

\subsubsection{Electrode Made of Cupper Foil}

Pulverized carbon nanofibers, carbon black (DENKA Black) and polyimide (varnish A) were mixed in the ratio of 75:10:15 wt \% and they were settled on the copper foil [3]. Afterwards, drying process for $1-2 \mathrm{~h}$ in a vacuum at $100{ }^{\circ} \mathrm{C}$ was carried out and it was then transferred to an electric furnace for calcination under flowing argon (flow rate; $500 \mathrm{~cm}^{3} / \mathrm{min}$ ). After finishing the calcination, the electrochemical sample was cut into a $\Phi 1.4 \mathrm{~cm}$ disc and dried for $24 \mathrm{~h}$ in a vacuum at $100{ }^{\circ} \mathrm{C}$. It was then moved into an argon glove box to prepare a CR2032-type coin battery. Ethylene carbonate (EC)/diethyl carbonate (DEC) (1:1) were added as electrolytes. The cell was assembled with a polyethylene microporous membrane separator and metal lithium foil. 
For electrochemical experiments of the coin cell, constant current (CC) charging/discharging was adopted. Current density was $30 \mathrm{~mA} / \mathrm{g}$, and charging/discharging processes ceased at $100 \mathrm{mV}$.

\section{Results}

\subsection{SEM/EDX Images}

Two samples (TEOS Carbon and TEOS/Si Hybrid Carbon) were created, as shown in Table 1. SEM/EDX images of them are presented in Figure 1a,b. Both samples exhibited long and continuous cylindrical morphologies with average diameter of $200-300 \mathrm{~nm}$. The distribution of carbon and $\mathrm{Si}$ is highlighted in red and green, respectively.

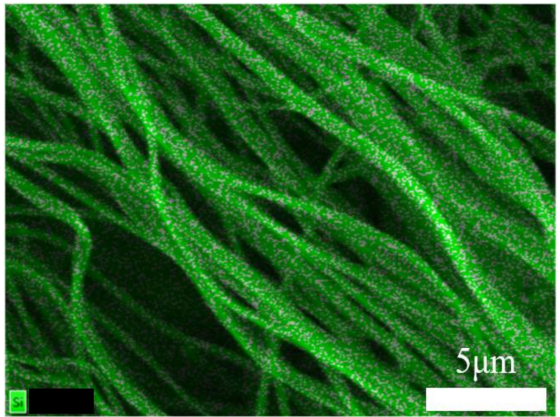

(a)

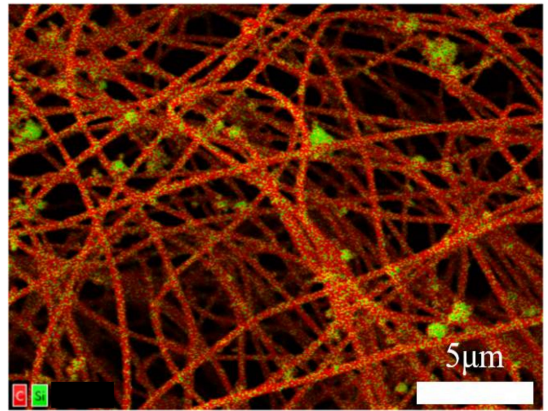

(b)

Figure 1. Elemental mapping data of: (a) TEOS Carbon; and (b) TEOS/Si Hybrid Carbon.

The elemental mapping data of TEOS Carbon (Figure 1a) indicates Si components are dispersed homogeneously in the carbon nanofibers. This is due to the mixed TEOS. It can be considered that the $\mathrm{Si}$ components are amorphous $\mathrm{SiO}_{2}$ and/or $\mathrm{SiOC}$ [4]. In addition, the elemental mapping data of TEOS/Si Hybrid Carbon (Figure 1b) indicates Si components and Si nanoparticles are dispersed homogeneously in/on the carbon nanofibers.

\subsection{TEM Images with Image Processing}

TEOS Carbon and TEOS/Si Hybrid Carbon were observed by TEM. Fourier transfer was, in addition, carried out and power spectra of the TEM images were obtained. The image processing technique is useful to analyze nanostructures [5]. TEM images and the corresponding power spectra are shown in Figure 2a,b.

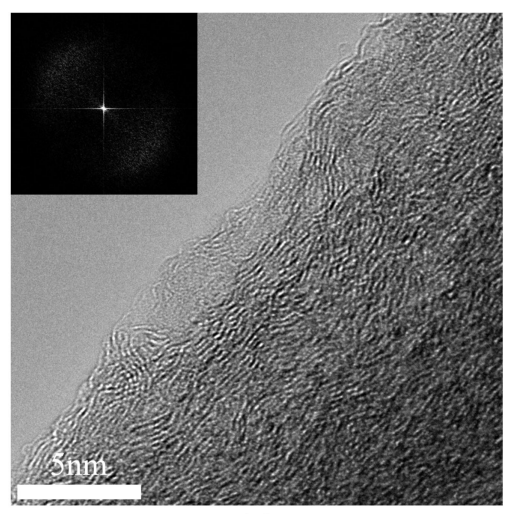

(a)

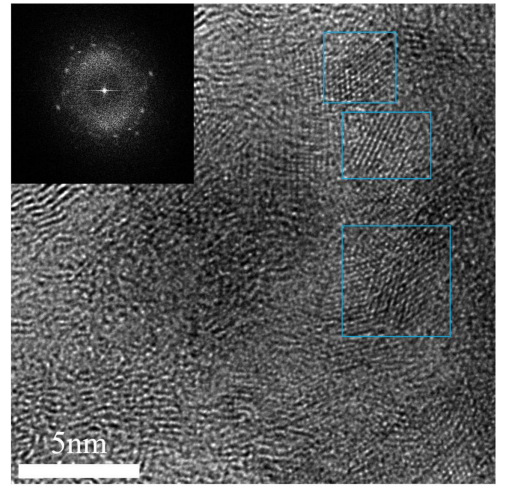

(b)

Figure 2. TEM images and the corresponding power spectra of: (a) TEOS Carbon; and (b) TEOS/Si Hybrid Carbon. 
As a result of observation, it was clarified that TEOS carbon has no Si crystal. The power spectrum of TEOS Carbon shown in Figure 2a also proves this fact. The result indicates TEOS generates amorphous $\mathrm{SiO}_{2}, \mathrm{SiOC}$ and/or $\mathrm{SiC}$. On the other hand, some Si nanoparticles were found in the carbon nanofibers, as shown in Figure $2 b$. This can be a solution for falling problem of the Si particles during charging/discharging.

\subsection{XRD Patterns}

Powder XRD using $\mathrm{CuK} \alpha$ radiation $(\lambda=0.15418 \mathrm{~nm})$ was adopted to determine the precise structures of two samples. XRD patterns of them are displayed in Figure 3a,b. Peculiar peaks of Si can be found from the XRD pattern of TEOS/Si Hybrid Carbon (Figure 3b), while XRD pattern of TEOS Carbon (Figure $3 \mathrm{a}$ ) has no peaks of Si. The result also proves Si components generated from TEOS are amorphous or in atomic state. From the position of the 002 peak $2 \theta$ in XRD, the interplanar spacing $d_{002}$ can be determined using the Bragg equation. $d_{002}$ of TEOS Carbon and TEOS/Si Hybrid Carbon were calculated to be $0.363 \mathrm{~nm}$ and $0.356 \mathrm{~nm}$, respectively.

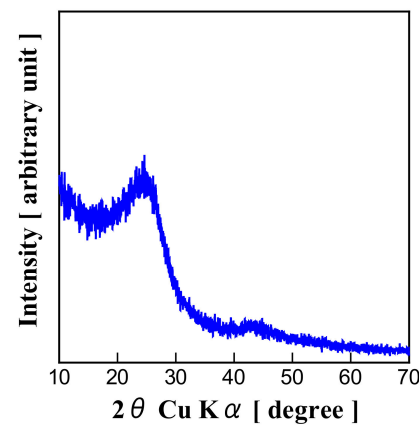

(a)

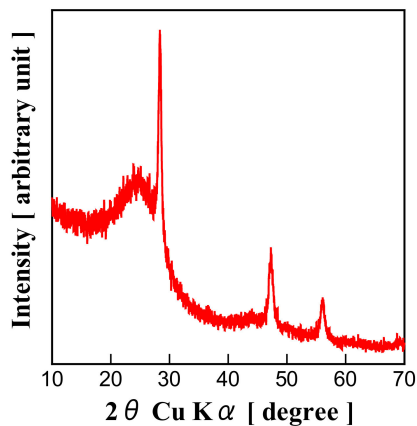

(b)

Figure 3. XRD patterns of: (a) TEOS Carbon; and (b) TEOS/Si Hybrid Carbon.

\subsection{Raman Spectra}

The Raman spectra of PAN-based Carbon, TEOS Carbon and TEOS/Si Hybrid Carbon are shown in Figure 4. In these Raman spectra, there are two large peaks called D-band and G-band. D-band is from amorphous structures of carbon, and appeared at around $1350 \mathrm{~cm}^{-1}$. G-band is graphitic structures of carbon, and appeared at around $1590 \mathrm{~cm}^{-1}$. They are used to obtain $\mathrm{R}$ ratio, intensity ratio $I_{\mathrm{D}} / I_{\mathrm{G}}$. The R ratio of PAN-based Carbon, TEOS Carbon and TEOS/Si Hybrid Carbon are calculated to be 1.01, 0.95 and 1.09, respectively. Additionally, peculiar peak of Si can be found at around $500 \mathrm{~cm}^{-1}$ in the Raman spectra of TEOS/Si Hybrid Carbon. This result reflects the effect of mixed Si nanoparticles. In the Raman spectra of TEOS Carbon, however, the broad band appears at around $500 \mathrm{~cm}^{-1}$. It is probable that this is due to a contribution from the amorphous SiOC related structure [4].

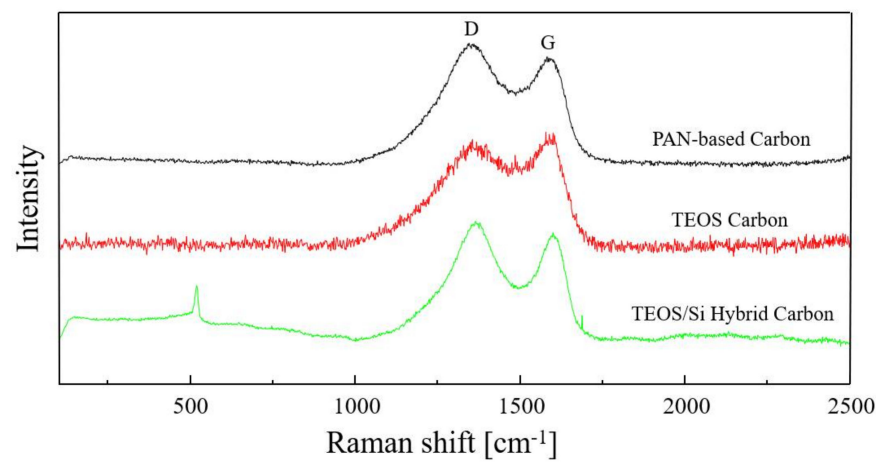

Figure 4. Raman spectra of PAN-based Carbon, TEOS Carbon and TEOS/Si Hybrid Carbon. 


\subsection{Electrochemical Characterization}

Galvanostatic charging/discharging curves of TEOS Carbon and TEOS/Si Hybrid Carbon are displayed in Figure 5a,b. Ni mesh-based electrode was adopted for electrochemical experiments of the TEOS Carbon, as shown in Section 2.3.1. Charging/discharging capacity for the second cycle was $483 \mathrm{mAh} / \mathrm{g}$ and $453 \mathrm{mAh} / \mathrm{g}$, respectively. They are higher than the theoretical capacity for graphite. Charging capacity for the first cycle was $842 \mathrm{mAh} / \mathrm{g}$. It is considerably higher than the theoretical capacity for graphite with a relatively large irreversible capacity of $355 \mathrm{mAh} / \mathrm{g}$. Discharging capacity decreases slowly with the progress of cycling.

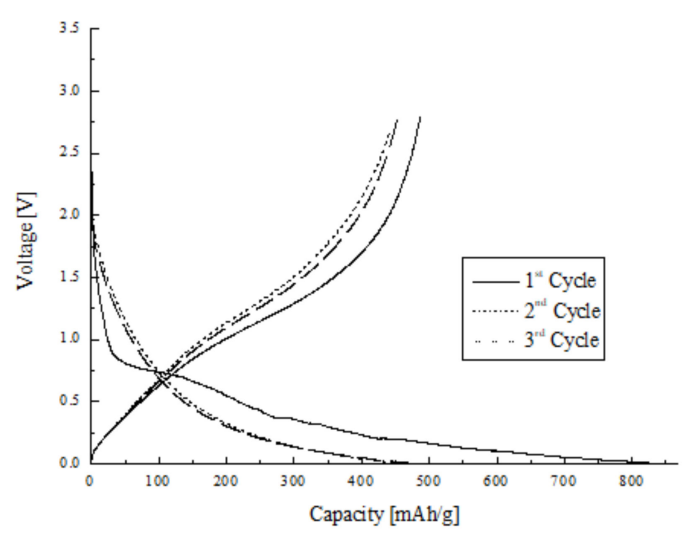

(a)

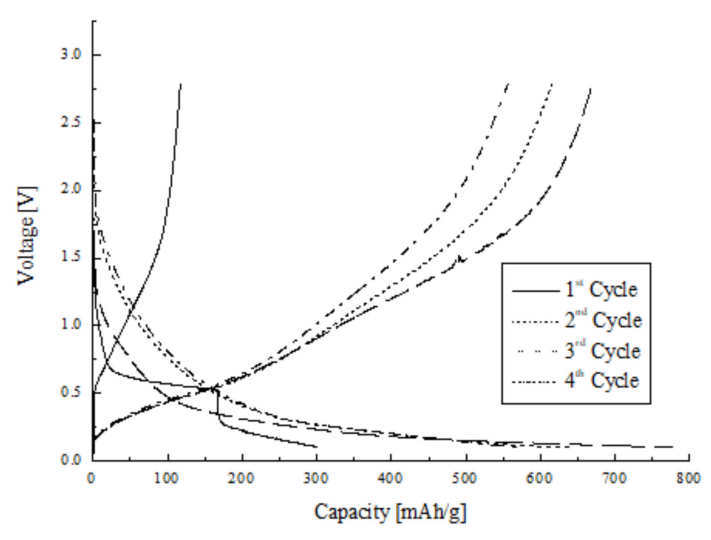

(b)

Figure 5. Charging/discharging curves of: (a) TEOS Carbon; and (b) TEOS/Si Hybrid Carbon.

$\mathrm{Cu}$ foil-based electrode was used for electrochemical experiments of the TEOS/Si Hybrid Carbon, as shown in Section 2.3.2. Charging/discharging capacity for the second cycle was $778 \mathrm{mAh} / \mathrm{g}$ and $670 \mathrm{mAh} / \mathrm{g}$, respectively. They are much higher than the theoretical capacity for graphite. It can be found that capacity for the first cycle is very low. This is because electrodes exhibit an activation process which is presumed to result from the gradual wetting process of the electrolyte [6]. In other words, in the first charging/discharging cycle of TEOS/Si Hybrid carbon, since Li ions did not easily enter Si particles, the capacity was smaller. The Si particles were activated during the first cycle and the capacity increased in the second cycle. In general, Si particles exhibit a well-defined discharging plateau at low voltage. As shown in Figure 5b, however, the place where the plateau usually appears is inclined. It can be considered that this is due to the mixed TEOS. Both TEOS and Si nanoparticles affected the charging/discharging capacity. In Figure 5b, there are two inflection points around 200 and $320 \mathrm{mAh} / \mathrm{g}$ in the second cycle discharging line. The plateau below $200 \mathrm{mAh} / \mathrm{g}$ is due to Si particles and the plateau between 200 and $320 \mathrm{mAh} / \mathrm{g}$ is due to TEOS compared to Figure $5 \mathrm{a}$.

\section{Discussion}

The present study developed TEOS Carbon and TEOS/Si Hybrid Carbon, electrode materials for the anode of LIB. The cell, consisting of Ni mesh-based electrode made of TEOS Carbon, exhibited a bit higher capacity (charging: $483 \mathrm{mAh} / \mathrm{g}$; discharging: $453 \mathrm{mAh} / \mathrm{g}$, second cycle) than the theoretical capacity for graphite. Discharging capacity of the sample decreased slowly with the progress of cycling. It can be considered that the high capacity was obtained not only because of TEOS, but also because of nanostructures of the carbon nanofibers. It is likely possible that the nanostructures of the carbon nanofibers were changed through carbonization at $100{ }^{\circ} \mathrm{C}$ combined with TEOS. The electrode made of TEOS/Si Hybrid Carbon using $\mathrm{Cu}$ foil exhibited a high capacity, almost two times higher than the theoretical capacity for graphite at the second cycle (charging: $778 \mathrm{mAh} / \mathrm{g}$; discharging: $670 \mathrm{mAh} / \mathrm{g}$ ). 
This is a substantial achievement of the research. Consequently, TEOS/Si Hybrid Carbon revealed that both TEOS and Si nanoparticles affected the charging/discharging capacity.

The content of $\mathrm{Si}$ in TEOS carbon was measured to be about $5 \mathrm{wt} \%$ by EDX. The discharging capacity of TEOS/Si hybrid carbon was 50\% higher than that of TEOS carbon. If the Si particles were $100 \%$ used, the amount of Si particles was about $5 \mathrm{wt} \%$ considering that the charging/discharging capacity of $\mathrm{Si}$ is $4200 \mathrm{mAh} / \mathrm{g}$. In fact, since Si particles were not $100 \%$ activated, the content of $\mathrm{Si}$ in the TEOS carbon and TEOS/Si Hybrid carbon was considered to be $10 \mathrm{wt} \%$ or more.

From the results of XRD and Raman spectroscopy, it was clarified that the two samples made in this research were hard-carbon-like materials. It is also obvious that 002 peaks of the two samples in XRD patters are broad and their calculated $d_{002}$ is wider than that of graphite (TEOS Carbon $d_{002}$ : $0.363 \mathrm{~nm}$, TEOS/Si Hybrid Carbon $d_{002}: 0.356 \mathrm{~nm}>$ Graphite $d_{002}: 0.3354 \mathrm{~nm}$ ). In addition, R ratio calculated from Raman spectra was not around that of graphite (TEOS Carbon R ratio: 0.95, TEOS/Si Hybrid Carbon R ratio: 1.09, Graphite powder R ratio: $0.19 \pm 0.02$ [7]). Since HEV and PHEV require batteries made of hard-carbon, it is highly possible that these two samples might be used for their batteries in the future.

Acknowledgments: This work was partly supported by grant-in-aid (No. 15K06004) of Ministry of Education, Sports, Culture, Science and Technology (MEXT), Japan, and Nanotechnology Platform Program (Molecule and Material Synthesis) of MEXT. Acknowledgments are also made to Analysis and Development System for Advanced Materials (ADAM) and Cooperative Studies Using Collaborative Research Facilities of Wood Composite of Research Institute for Sustainable Humanosphere of Kyoto University. Moreover, this work was partly supported by grant-in-aid of The Foundation for Applied Research and Technological Uniqueness at Nagaoka University of Technology.

Author Contributions: Kyoichi Oshida conceived and designed the experiments; Takunori Minamisawa, Nozomi Kobayashi and Daiki Misawa performed the overall experiments; Akinobu Ando carried out the image processing and analyzed TEM images; Tomoyuki Itaya contributed regents/materials/measurement tools; Minoru Moriyama, Kozo Osawa and Toshimitsu Hata gave technical advice on electrospinning; Yuta Sugiyama and Hiroto Iguchi performed Raman spectroscopy experiments and gave some advices on electrochemical experiments; Naoya Kobayashi contributed materials and gave technical advice on silicon and LIB; and Takunori Minamisawa wrote the paper.

Conflicts of Interest: The authors declare no conflict of interest.

\section{References}

1. Zhang, W.-J. A Review of the Electrochemical Performance of Alloy Anodes for Lithium-Ion Batteries. J. Power Sources 2011, 196, 13-24. [CrossRef]

2. Inagaki, M.; Yang, Y.; Kang, F. Carbon Nanofibers Prepared via Electrospinning. Adv. Mater. 2012, 24, 2547-2566. [CrossRef] [PubMed]

3. Kobayashi, N.; Inden, Y.; Endo, M. Silicon/soft-carbon nanohybrid material with low expansion for high capacity and long cycle life lithium-ion battery. J. Power Sources 2016, 326, 235-241. [CrossRef]

4. Kim, S.Y.; Kim, B.-H.; Yang, K.S.; Oshida, K. Supercapacitive properties of porous carbon nanofibers via the electrospinning of metal alkoxide-graphene in polyacrylonitrile. Mater. Lett. 2012, 87, 157-161. [CrossRef]

5. Oshida, K.; Murata, M.; Fujiwara, K.; Itaya, T.; Yanagisawa, T.; Kimura, K.; Nakazawa, T.; Kim, Y.A.; Endo, M.; Kim, B.-H.; et al. Structural analysis of nano structured carbon by transmission electron microscopy and image processing. Appl. Surf. Sci. 2013, 275, 409-412. [CrossRef]

6. Yin, S.; Ji, Q.; Zuo, X.; Xie, S.; Fang, K.; Xia, Y.; Li, J.; Qiu, B.; Wang, M.; Ban, J.; et al. Silicon lithium-ion battery anode with enhanced performance: Multiple effects of silver nanoparticles. J. Mater. Sci. Technol. 2018. [CrossRef]

7. Jasim, D.A.; Lozano, N.; Kostarelos, K. Synthesis of few-layered, high-purity graphene oxide sheets from different graphite sources for biology. 2D Mater. 2016, 3, 1-17. [CrossRef] 